\title{
$\beta$-位にニトロ基をめつリン化合物の官能基変換 反応およびリン糖の合成
}

\author{
(1986 年 10 月 31 日受理) \\ 山下光司* • 山田学・杉浦基之・野本浩通・押川達夫
}

\begin{abstract}
ニトロオレフィン類に H-P 結合をもつリン化合物を反応させると, 新たに C-P 結合を形成し, $\beta-$ 位にニト口基をもつリン化合物が生成した。このニトロ基の変換は，従来の Nef 反応などを用いた反 応では進行しなかったが，塩基存在下でのオゾンや一重項酸素との反応では進行し，アルデヒド誘導体 へと高収率で変換できた。アルデヒド誘導体は還元剤によりアルコール誘導体へと変換でき，この方法 により,リン糖の骨格の一部分を合成する方法が開発された。これら一連の反応を利用して若干のリン 糖合成に成功した。
\end{abstract}

\section{1 緒 言}

“糖のヒドロキシル基をアミノまたはメルカプト基で置き換えた 化合物や，へミアセタール環内の酸素原子を窒素または硫黄原子 で置き換えた化合物は，一般にアミノ糖またはチ才糖と呼ばれ， 合成例も多く，また天然にも存在することが知られている1) 3)。 一方，対応するリン誘導体は，リン糖と呼ばれるが，合成例は少 なく，天然に存在することは今までのところ知られていない(4)1。 アミノ糖やチオ桾については，合成および構造の面のみでな く，生理活性についても広く研究されている。たとえば, アミ， 糖である 5-アミノ-5-デオキシ-D-グルコースはノジリマイシン といら抗生物質として知られている ${ }^{2617)}$ 。チオ糖である5-デオキ シ-5-チオーD-グルコピラノースは血糖濃度を增加させる作用を有 し8)，2,4-ジデオキシ-4-チオーD-リボフラノースのヌクレオシド

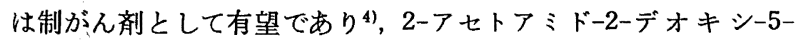
チオーD-グルュース拉よび -D-マンノースはがんの治療への応用 の可能性がある97。

静岡大学工学部応用化学科, 432 浜松市城北

1) M. J. R. Salton, Annu. Rev. Biochem., 35, 485(1966).

2) S. Inouye, T. Tsuruoka, T. Niida, J. Antibiot. (Tokyo), Ser. A, 19, 288(1966).

3) H. Paulsen, Angew. Chem., 78, 501(1966).

4) 猪川三郎, 化学, 24, 901(1969).

5) H. Yamamoto, S. Inokawa, Adv. Carbohydr. Chem. Biochem., 42, 135(1984).

6) S. Hanessian, "Total Synthesis of Natural Products : The 'Chiron' Approach," Pergamon Press, Oxford (1983) p. 228.

7) S. Inouye, T. Tsuruoka, T. Ito, T. Niida, Tetrahedron, 24, 2125(1968).

8) U. G. Nayak, R. L. Whistler, J. Org. Chem., 34, 97 (1969).

9) R. Csuk, B. I. Glänzer, J. Chem. Soc., Chem. Commun., 1986, 343.
リン酸エステルのーO-結合を等電子構造をむつ- $\mathrm{CH}_{2}$-結合で置

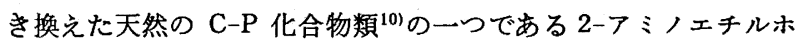
スホン酸が 1959 年に堀ロらにより発見され(1), その後数種のリ ン脂質やリンタンパク質か゚自然界に存在することが見いだされ た(10)。また，それらのホスホン酸誘導体の代謝の機構についての 研究が行なわれた12)。

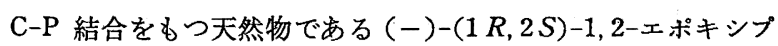
ロピルホスホン酸(ホスホノマイシン) は抗ビイルス活性をるつ 抗生物質であり，その他の $\mathrm{C}-\mathrm{P}$ 結合をむつ抗生物質類も知られ ている ${ }^{13)(4)}$ 。た，リンを含むへテロ環状化合物であるシクロホ スファミドは重要な抗腫啕性の医薬品である ${ }^{15 !} 。$

現在までのところ, リン糖については合成例も少なく，その生 理活性についての報告例も少ないが, 5-デオキシ-1, 5-C-(エチル ホスフィニリデン)- $\beta$-D-グルコースのアセチル誘導体では弱い 抗がん作用があることが明らかになっだ!。上記のようなへテロ 糖, C-P 化合物, リンを含む複素環式化合物の生化学的性質から

10) M. Kandatsu, "Biochemistry of Natural C-P Compounds," ed. by T.Hori, M. Horiguchi, A. Hayashi, Maruzen, Kyoto (1984) Chapt. 1.

11) M. Horiguchi, M. Kandatsu, Natare, 184, 901(1959).

12) D. E.C. Corbridge, "Phosphorus: An Outline of its Chemistry, Biochemistry, and Technology," Elsevier, Amsterdam (1985) Chapt. 11.

13) R. L. Hilderbrand, J. Curley-Joseph, H. J. Lubansky, T. O. Henderson, "Topics in Phosphorus Chemistry," ed. by M. Grayson, E. J. Griffith, John Wiley, New York (1983) Vol. 11 Chapt. 4.

14) M. Horiguch1, "Biochemistry of Natural C-P Compounds," ed. by T. Hori, M. Horiguchi, A. Hayashi, Maruzen, Kyoto (1984) Chapt. 6.

15) K. Domroth, "Comprehensive Heterocyclic Chemistry: The Structure, Reactions, Synthesis and Uses of Heterocyclic Compounds, " ed. by A. R. Katritzky, Pergamon Press, Oxford (1984) Vol.1, Chapt. 17. 
類推して、リン糖に执いては抗がん作用などの生理活性の発現が 期待できるものと考学られる。

それゆえに，C-P，結合をるつリン糖の合成は重要な研究課題で あると思われる。

リン糖合成に批ける重要な段階は，糖の骨格炭素上にリン原子 を結合し，4-デオキシ-4-C-ホスフィニルまたは，5-デオキシ-5$C$-ホスフィニル型の糖誘導体を合成する段階である。リン誘導体 においては, 糖の骨格炭素ーリン結合形成とつづく官能基変換反 応が、アミノまたはチオ糖に扰ける炭素一へテロ原子結合形成反 応と比較して大変に難しい点が，リン糖合成を現在までのところ いちじるしく困難にしている要因である。

炭素ーリン結合形成反応はすでに種々知られているが，リン原 子の求核性を利用した反応である Michaelis-Arbuzov 反応や Michaelis-Becker 反応はそのうちの代表的な反応である る16)1 。 前者の反応は第一級炭素原子ヘリン原子を結合させる場合には簡 便で優れた方法ではあるが第二級炭素原子上での反応性は悪い。 また，後者の反応は第二級炭素原子上でも進行するので，より広 い応用が期待できる。ジヒドリドビス(2-メトキシェタノラト)ア ルミン酸ナトリウム (SDMA) により発生したリン陰イオンを用 いた SN 2 反応により，立体特異的に炭素ーリン結合を形成する方 法も知られている ${ }^{18) 199}$ 。しかしこれらの求核置換反応を用いた 炭素ーリン結合形成反応をリン糖合成に利用するさいには，立体 障害などの困難をともなう。

他方, 多重結合へのリン化合物の付加反応による炭素ーリン結 合の形成も種々知られている200。電子求引基をるつ炭素-炭素二 重結合に対してリン化合物は容易に付加し，電子求引基のない炭 素原子上にリン原子を導入することができる。この反応によれば
第二級炭素原子上にリン原子が結合した化合物を得ることができ るが，付加反応のさいの立体選択性に問題がある。

この論文では, ニトロ基により活性化された炭素-炭素二重結 合へのリン化合物の付加反応を用いた炭素ーリン結合をもつ化合 物の合成と，そのニトロ基の官能基変換反応について報告し， あ わせて，その反応を利用したりン糖合成についても報告する。

\section{2 結 果 と考 察}

ニトロオレフィン〔1]にジフェニルホスフィンオキシドを $\mathrm{THF}$ 中室温にて作用させると，付加物である [(1-ニトロメチ ル)アルキル]ジフェニルスフィンオキシド〔2〕が得られた。

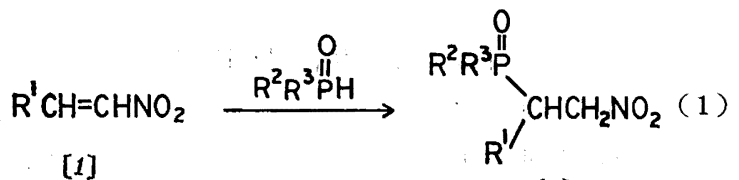

[2]

$\mathrm{R}^{1}=\mathrm{Me}, \mathrm{Et}, n-\mathrm{Pr}, i-\mathrm{Pr}, \mathrm{Ph}$ $\mathrm{R}^{2}=\mathrm{Ph}, \mathrm{OMe}$ $\mathrm{R}^{3}=\mathrm{Ph}, \mathrm{OMe}$

ニトロエチレン（[1]， R=H）の場合には，重合反応が優先し て進行するために付加物〔2]は得られなかった。フェニルホス フィン酸メチルやホスホン酸ジメチルも付加物〔3]を与えた。 この結果を表 1 に示す。

化合物〔2]のニトロ基を変換してアルデヒド誘導体〔3]を 合成する反応について検討した。ニトロ化合物からアルデヒド誘 導体を合成する方法としては，強酸性条件下の反応（Nef 反

Table $1 \beta$-Nitro phosphorus compounds [2] prepared from nitroalkenes

\begin{tabular}{clllcc} 
Compound & $\mathrm{R}^{1}$ & $\mathrm{R}^{2}$ & $\mathrm{R}^{3}$ & $\mathrm{mp} /{ }^{\circ} \mathrm{C}\left(\right.$ or $\left.\mathrm{bp} /{ }^{\circ} \mathrm{C} / \mathrm{mmHg}\right)$ & Yield $\%$ \\
\hline$[2 \mathrm{a}]$ & $\mathrm{Me}$ & $\mathrm{Ph}$ & $\mathrm{Ph}$ & $120 \sim 123$ & 93 \\
{$[2 \mathrm{~b}]$} & $\mathrm{Et}$ & $\mathrm{Ph}$ & $\mathrm{Ph}$ & $115 \sim 117$ & 118 \\
{$[2 \mathrm{c}]$} & $n-\mathrm{Pr}$ & $\mathrm{Ph}$ & $\mathrm{Ph}$ & 160 & 96 \\
{$[2 \mathrm{~d}]$} & $i-\mathrm{Pr}$ & $\mathrm{Ph}$ & $\mathrm{Ph}$ & $208 \sim 209$ & 95 \\
{$[2 \mathrm{e}]$} & $\mathrm{Ph}$ & $\mathrm{Ph}$ & $\mathrm{Ph}$ & & 86 \\
{$[2 \mathrm{f}]$} & $\mathrm{Me}$ & $\mathrm{Ph}$ & $\mathrm{OMe}$ & & $46^{a)}$ \\
{$[2 \mathrm{~g}]$} & $\mathrm{Et}$ & $\mathrm{Ph}$ & $\mathrm{OMe}$ & & $53^{a)}$ \\
{$[2 \mathrm{~h}]$} & $i-\mathrm{Pr}$ & $\mathrm{Ph}$ & $\mathrm{OMe}$ & $(102 / 0.2)$ & $\left.19^{a}\right)$ \\
{$[2 \mathrm{i}]$} & $\mathrm{Me}$ & $\mathrm{OMe}$ & $\mathrm{OMe}$ & $(90 / 0.1)$ & 55 \\
{$[2 \mathrm{j}]$} & $\mathrm{Et}$ & $\mathrm{OMe}$ & $\mathrm{OMe}$ & $(91 / 0.05)$ & 51 \\
{$[2 \mathrm{k}]$} & $n-\mathrm{Pr}$ & $\mathrm{OMe}$ & $\mathrm{OMe}$ & $(120 / 0.2)$ & 57 \\
{$[21]$} & $i-\mathrm{Pr}$ & $\mathrm{OMe}$ & $\mathrm{OMe}$ & $(111 \sim 112)$ & 60 \\
{$[2 \mathrm{~m}]$} & $\mathrm{Ph}$ & $\mathrm{OMe}$ & $\mathrm{OMe}$ & & 5
\end{tabular}

a) Purified by chromatography on silica gel.

16) A.J. Kirby, S. G. Warren, "The Chemistry of Phosphorus," Elsevier, Amsterdam (1967) pp. 37-45.

17) J.I. G. Cadogan, "Organophosphorus Reagents in Organic Synthesis," ed. by J.I.G. Cadogan, Academic Press, London (1979) Chapt. 1.

18) M. Yamashita, N. Suzuki, M. Yamada, Y. Soeda, H. Yamashita, K. Nakatani, T. Oshikawa, S. Inokawa, Bull. Chem. Soc. Jpn., 56, 219(1983).

19) M. Yamashita, Y.Soeda, N.Suzuki, M. Yamada, K. Tsunekawa, T. Oshikawa, S. Inokawa, ibid., 56,|1871 (1983).
20) A. J. Kirby, S. G. Warren, "The Chemistry of Phos phorus," Elsevier, Amsterdam (1967) pp. 45 63.

21) W. E. Nolan, Chem. Rev., 55, 137(1955).

22) H. Shechter, F. T. Williams, Jr., J. Org. Chem., 27, 3699(1962).

23) A. H. Pagano, H. Shechter, ibid., 35, 295(1970).

24) J. E. McMurry, J. Melton, H. Padgett, ibid., 39, 259 (1974).

25) P. A. Bartlett, F. R. Green, III, T. R.Webb, Tetrahedron Lett., 1977, 331. 


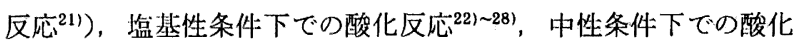

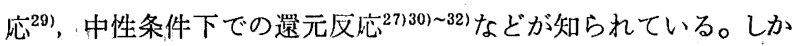
し， $\beta$-炭素上にニトロ基をもったりン化合物をアルデヒド誘導体 へと変換する反応は知られていない。上記の種々の二トロ基変換 反応を化合物〔2]について試みたが，それらは進行しなかっ た25)27)28)30182)。

オン゙ンにより炭素-炭素二重結合を切断して，ケトンまたはア ルデヒドを合成する方法は知られている2433)。ナトリウムメトキ シドの存在下, 化合物〔2]をオゾンで処理し, その後硫化ジメ チルを加え，後処理ののち生成物を取りたすと，対応するアルデ

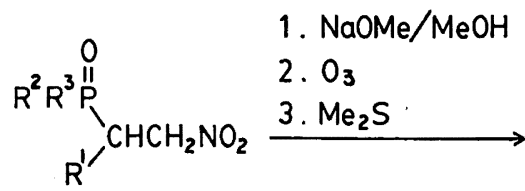

[2]

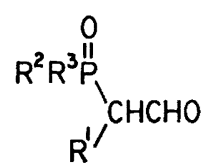

[3]
ヒド誘導体〔3]が得られた。

化合物 [3]には, IR スペクトルに拀いて〔2]のニトロ基に 起因する 1545 扣よび $1375 \mathrm{~cm}^{-1}$ の吸収がなく，1720, $1650 \mathrm{~cm}^{-1}$ 付近に新しくカルボニル基に起因する吸収が現われ，また ${ }^{1} \mathrm{H}-$ NMR スペクトルにおいてはニトロ基の $\alpha$-位のメチレンに帰属 される $\delta 4.5 \sim 4.8$ のシグナルが消失し， $\delta 9.8$ 付近にフルデヒド プロトンに帰属されるシグナルが現われることにより，化合物 〔2〕から〔3]への変換反応が進行したことが示された。また, 元素分析や質量スペクトルからも〔3]の構造が支持された。こ れらの結果を表 2 に示す。この変換反応は中間に生じるニトロン 酸塩の $\mathrm{C}=\mathrm{N}$ 結合のオゾン分解であると思われる。化合物 [3] は 2,4 -ジニトロフェニルヒドラゾンに誘導された。

化合物〔2]をナトリウムメトキシド存在下, 一重項酸素と反 応させることによっても，また〔3]を得ることができだ4)。 の結果を表 3 に示す。

アルデヒド〔3〕を還元しアルコール誘導体〔4〕を合成した。 還元には， $\mathrm{R}^{\prime}=\mathrm{Ph}$ のときにはシアノトリヒドロホウ酸ナトリウ ムを，そのほかの場合には水素化ホウ素ナトリウムを用いた。化

Table 2 Aldehydes [3] prepared by ozone method

\begin{tabular}{|c|c|c|c|c|c|}
\hline Aldehyde & $\mathrm{R}^{1}$ & $\mathrm{R}^{2}$ & $\mathrm{R}^{3}$ & $\mathrm{mp} /{ }^{\circ} \mathrm{C}\left(\right.$ or $\left.\mathrm{bp} /{ }^{\circ} \mathrm{C} / \mathrm{mmHg}\right)$ & Yield $/ \%$ \\
\hline$[3 \mathrm{a}]$ & $\overrightarrow{\mathrm{Me}}$ & $\mathrm{Ph}$ & $\mathrm{Ph}$ & $130 \sim 131$ & 90 \\
\hline$[3 \mathrm{~b}]$ & Et & $\mathrm{Ph}$ & $\mathrm{Ph}$ & $147 \sim 148$ & 99 \\
\hline$[3 \mathrm{~d}]$ & $i-\operatorname{Pr}$ & $\mathrm{Ph}$ & $\mathrm{Ph}$ & $168 \sim 169$ & 90 \\
\hline$[3 \mathrm{e}]$ & $\mathrm{Ph}$ & $\mathrm{Ph}$ & $\mathrm{Ph}$ & $189 \sim 190$ & 67 \\
\hline$[3 \mathrm{f}]$ & $\mathrm{Me}$ & $\mathrm{Ph}$ & $\mathrm{OMe}$ & & $95^{a)}$ \\
\hline$[3 \mathrm{~g}]$ & Et & $\mathrm{Ph}$ & $\mathrm{OMe}$ & & $90^{a)}$ \\
\hline$[3 \mathrm{~h}]$ & $i-\mathrm{Pr}$ & $\mathrm{Ph}$ & $\mathrm{OMe}$ & & $75^{a)}$ \\
\hline [3i] & $\mathrm{Me}$ & $\mathrm{OMe}$ & $\mathrm{OMe}$ & $(74 / 0.1)$ & $38(76)^{b)}$ \\
\hline$[3 \mathrm{j}]$ & Et & $\mathrm{OMe}$ & $\mathrm{OMe}$ & $(75 / 0.1)$ & $44(85)^{b)}$ \\
\hline [31] & $i-\operatorname{Pr}$ & $\mathrm{OMe}$ & $\mathrm{OMe}$ & $(80 / 0.1)$ & $35(80)^{b)}$ \\
\hline$[3 \mathrm{~m}]$ & $\mathrm{Ph}$ & $\mathrm{OMe}$ & $\mathrm{OMe}$ & $106 \sim 108$ & $30(88)^{b)}$ \\
\hline
\end{tabular}

a) Purified by chromatography on silica gel.

b) Values in parenthesis indicate yields determined by ${ }^{1} \mathrm{H}-\mathrm{NMR}$.

Table 3 Aldehydes [3] prepared by singlet oxygen method

\begin{tabular}{clllcr} 
Aldehyde & $\mathrm{R}^{1}$ & $\mathrm{R}^{2}$ & $\mathrm{R}^{3}$ & $\mathrm{mp} /{ }^{\circ} \mathrm{C}$ (or bp/ ${ }^{\circ} \mathrm{C} / \mathrm{mmHg}$ ) & Yield $/ \%$ \\
\hline$[3 \mathrm{a}]$ & $\mathrm{Me}$ & $\mathrm{Ph}$ & $\mathrm{Ph}$ & $130 \sim 131$ & $147 \sim 148$ \\
{$[3 \mathrm{~b}]$} & $\mathrm{Et}$ & $\mathrm{Ph}$ & $\mathrm{Ph}$ & $148 \sim 149$ & 90 \\
{$[3 \mathrm{c}]$} & $n-\mathrm{Ph}$ & $\mathrm{Ph}$ & $\mathrm{Ph}$ & $168 \sim 169$ & 97 \\
{$[3 \mathrm{~d}]$} & $i-\mathrm{Pr}$ & $\mathrm{Ph}$ & $\mathrm{Ph}$ & $189 \sim 190$ & 91 \\
{$[3 \mathrm{e}]$} & $\mathrm{Ph}$ & $\mathrm{Ph}$ & $\mathrm{Ph}$ & $(63 / 0.2)$ & 87 \\
{$[3 \mathrm{i}]$} & $\mathrm{Me}$ & $\mathrm{OMe}$ & $\mathrm{OMe}$ & $(70 / 0.2)$ & 80 \\
{$[3 \mathrm{j}]$} & $\mathrm{Et}$ & $\mathrm{OMe}$ & $\mathrm{OMe}$ & $(76 /<0.1)$ & 90 \\
{$[3 \mathrm{k}]$} & $n-\mathrm{Pr}$ & $\mathrm{OMe}$ & $\mathrm{OMe}$ & $(81 / 0.1)$ & 70 \\
{$[31]$} & $i-\mathrm{Pr}$ & $\mathrm{OMe}$ & $\mathrm{OMe}$ & $106 \sim 108$ & 64 \\
{$[3 \mathrm{~m}]$} & $\mathrm{Ph}$ & $\mathrm{OMe}$ & $\mathrm{OMe}$ & & 73
\end{tabular}

26) M. R. Galobardes, H. W. Pinnick, Tetrahepron Lett., 1981, 5235.

27) G. A. Olah, B. G. B. Gupta, Synthesis, 1980, 44.

28) E. Keinan, Y. Mazur, J. Am. Chem. Soc., 99, 3861 (1977).

29) N. Kornblum, P. A. Wade, J. Org. Chem., 38, 1418 (1973).

30) J. E. McMurry, J. Melton, J. Am. Chem. Soc., 93, 5309(1971).

31) R. Kirchhoff, Tetrahedron Lett., 1976, 2533.
32) G. A. Olah, B. G. B. Gupta, S. C. Narang, R. Malhotra, J. Org. Chem., 44, 4272(1979).

33) A. H. Haines, "Methods for the Oxidation of Organic Compounds," Academic Press, London (1985) p. 119.

34) A.P.Schaap, K. A. Zaklika, "Singlet Oxygen," ed. by H. H. Wasserman, R. W. Murray, Academic Press, New York (1979) Chapt. 6.

35) H. Takayanagi, M. Yamashita, K. Seo, H. Yoshida, T. Ogata, S. Inokawa, Carbohydr. Res., 38, C 19 (1974). 
Table 4 Alcohols [4] prepared from aldehydes [3]

\begin{tabular}{clllccc} 
Alcohol & $\mathrm{R}^{1}$ & $\mathrm{R}^{2}$ & $\mathrm{R}^{3}$ & $\mathrm{mp} /{ }^{\circ} \mathrm{C}$ & Yield $/ \%$ & $\mathrm{IR} / \mathrm{cm}^{-1}(\mathrm{OH})$ \\
\hline$[4 \mathrm{a}]$ & $\mathrm{Me}$ & $\mathrm{Ph}$ & $\mathrm{Ph}$ & $141 \sim 142$ & 82 & 3200 \\
{$[4 \mathrm{~b}]$} & $\mathrm{Et}$ & $\mathrm{Ph}$ & $\mathrm{Ph}$ & $105 \sim 106$ & 89 & 3300 \\
{$[4 \mathrm{~d}]$} & $i-\mathrm{Pr}$ & $\mathrm{Ph}$ & $\mathrm{Ph}$ & 148 & 92 & 3350 \\
{$[4 \mathrm{e}]$} & $\mathrm{Ph}$ & $\mathrm{Ph}$ & $\mathrm{Ph}$ & $168 \sim 170$ & 63 & 3400 \\
{$[4 \mathrm{f}]$} & $\mathrm{Me}$ & $\mathrm{Ph}$ & $\mathrm{OMe}$ & & 85 & 3275 \\
{$[4 \mathrm{~g}]$} & $\mathrm{Et}$ & $\mathrm{Ph}$ & $\mathrm{OMe}$ & & 91 & 3350 \\
{$[4 \mathrm{~h}]$} & $i-\mathrm{Pr}$ & $\mathrm{Ph}$ & $\mathrm{OMe}$ & & 75 & 3300 \\
{$[4 \mathrm{i}]$} & $\mathrm{Me}$ & $\mathrm{OMe}$ & $\mathrm{OMe}$ & & $24^{a}$ & 3400 \\
{$[4 \mathrm{j}]$} & $\mathrm{Et}$ & $\mathrm{OMe}$ & $\mathrm{OMe}$ & & $13^{a}$ & 3400 \\
{$[41]$} & $i-\mathrm{Pr}$ & $\mathrm{OMe}$ & $\mathrm{OMe}$ & & $18^{a)}$ & 3400 \\
{$[4 \mathrm{~m}]$} & $\mathrm{Ph}$ & $\mathrm{OMe}$ & $\mathrm{OMe}$ & & $65^{a}$ & 3400
\end{tabular}

a) Purified by thin layer chromatography on silica gel.

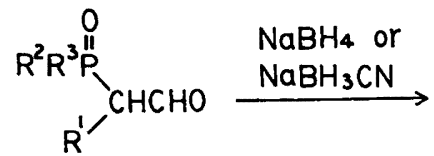

[3]<smiles>[R2][R](=O)C([R])CO</smiles>

[4]
合物 [4]の構造は元素分析, ${ }^{1} \mathrm{H}-\mathrm{NMR}, \mathrm{IR}$, 質量スペクトルに よって確認された。この結果を表 4 に示す。化合物〔4〕はピリ シシン溶液中で無水酢酸の作用を受けて，対応する酢酸エステル誘 導体を与えた。これにより, リン糖の部分骨格をるつ化合物が合 成された。

上記の反応を、ニトロエノースを経るリン糖合成の経路に応用 した。5,6-ジデオキシ-1, 2-O-イソプロピリデン-3-O-メチル-6-

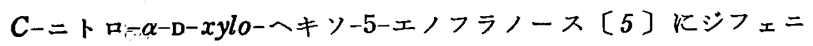
ルホスフィンオキシドなどのリン化合物を作用させると付加物

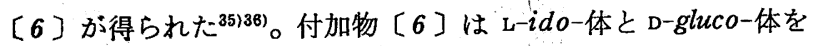

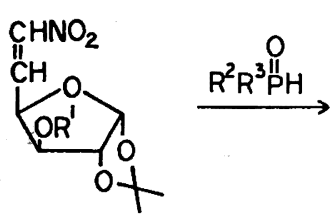

[5]

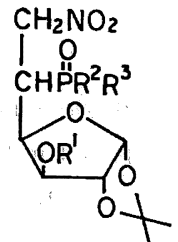

[6]
含み, その比はシフェニルホスフィンオキシド付加体 $[6 \mathrm{a}]$ の場 合には $11: 1$ であった。その結果を表 5 に示す。L-ido-体が多い のは, リンの付加のさいに立体障害がより小さいためであると思

Table 5 Isomer ratios of compounds [6]

\begin{tabular}{clllrl} 
Compound & $\mathrm{R}^{1}$ & $\mathrm{R}^{2}$ & $\mathrm{R}^{3}$ & \multicolumn{2}{c}{ Isomer ratio } \\
\cline { 5 - 6 } & & & & L-ido $:$ D-gluco \\
\hline$[6 \mathrm{a}]$ & $\mathrm{OMe}$ & $\mathrm{Ph}$ & $\mathrm{Ph}$ & $11:$ & 1 \\
{$[6 \mathrm{~b}]$} & $\mathrm{OMe}$ & $\mathrm{Ph}$ & $\mathrm{H}$ & $3.8:$ & 1 \\
{$[6 \mathrm{c}]$} & $\mathrm{OAc}$ & $\mathrm{Ph}$ & $\mathrm{H}$ & $3.5:$ & 1 \\
{$[6 \mathrm{~d}]$} & $\mathrm{OMe}$ & $\mathrm{OMe}$ & $\mathrm{OMe}$ & $2:$ & 1 \\
{$[6 \mathrm{e}]$} & $\mathrm{OBn}$ & $\mathrm{OMe}$ & $\mathrm{OMe}$ & $3:$ &
\end{tabular}

36) P. Luger, M. Yamashita, S. Inokawa, Carbohydr. Res., 84, 25(1980).

われる。

5,6-ジデオキシ-5-C-(ジフェニルホスフィニル)-1, 2-O-イソ プロピリデン-3-O-メチル-6-C-ニトロ- $\beta-\mathrm{L}-$ イドフラノース〔6 $\mathrm{a}, i d o]$ をナリウムメトキシド存在下でオン゙ンと反応させると, アルデヒド誘導体〔7〕が $97 \%$ の収率で得られた。水素化ホウ 素ナトリウムを用いて〔7]を睘元するとヒドロキシ誘導体 [8] が 65\% の収率で得られた。〔8〕はido-体怙よび gluco-体をふ たたび $11: 1$ の割合で含んでいた。変換のさいの塩基により ido 一体の一部が異性化して gluco-体になったと思われる。化合物 〔8〕はアセチル化により〔9]炋誘導された。
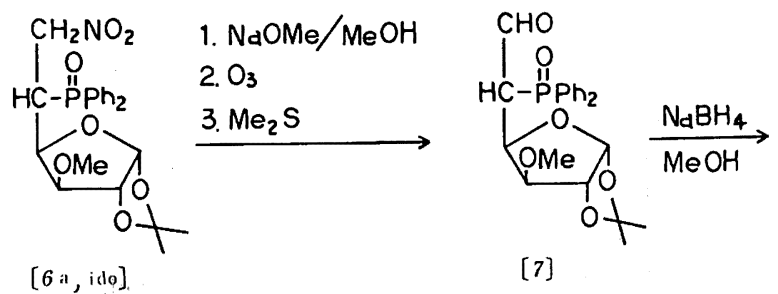

[7]

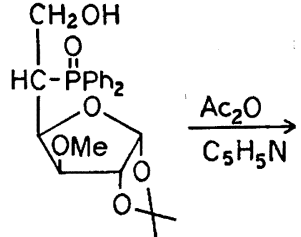

[8]

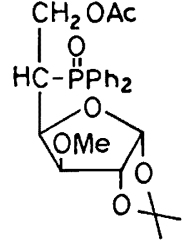

[9]
(5)

エノース [5]とフェニルホスフィンとの付加反応生成物であ る 5, 6-ジデオキシ-1, 2-O-イソプロピリデン-3-O-メチル-6-Cニトロ-5-C-(フェニルホスフィノ) $-\beta-\mathrm{L}-$ イドフラノース $[6 \mathrm{~b}$, $i d o 〕 を 0.7 \mathrm{~mol} \cdot \mathrm{dm}^{-3}$ 塩酸と加樊還流してへミアセタール環内 にリン原子をもつ化合物〔10]を得た。化合物〔10]にナトリウ ムメトキシド存在下, メタノール中でオゾンを $-78^{\circ} \mathrm{C}$ にて作用 させると, アルデヒド〔11〕が $82 \%$ の収率で得られた。アルデ ヒド〔11〕を水素化ホウ素ナトリウムで還元すると, アルコール 〔12〕が定量的に得られた。アルコール〔12〕をピリジン中無水酢 酸によりアセチル化して，1，2，4，6-テトラーO-アセチル-5-デオ キシ-3-O-メチル-1,5-C-(フェニルホスフィニリデン) $-\alpha, \beta-L-$ イドース〔13]を得た。[13]の収率は, ニトロ化合物 $[6 \mathrm{~b}, i d o]$ から $3.2 \%$ であった。化合物 [10], 〔11]，〔12]，〔13]の $C_{1}$ お。 


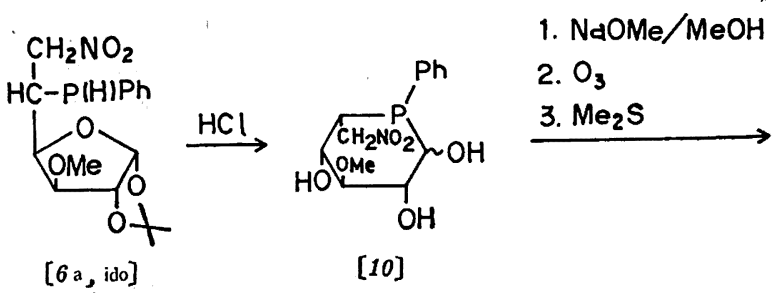<smiles>O=P1(c2ccccc2)C(O)C2CCC(O2)C1O</smiles>

[11]

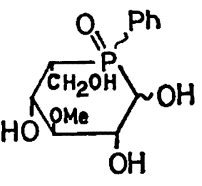

[12]

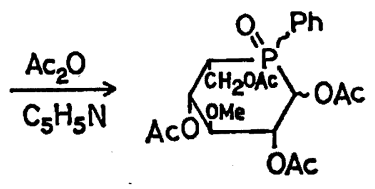

[13]

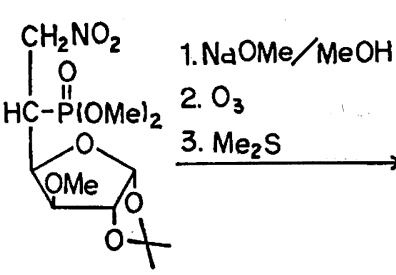

[6d]

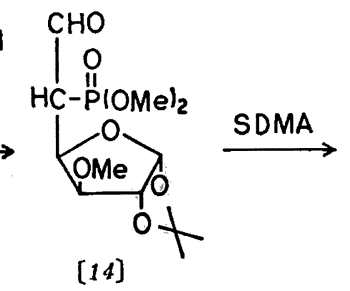

[14]

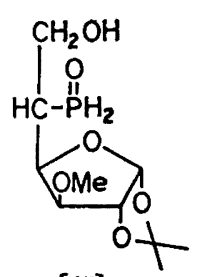

[15]

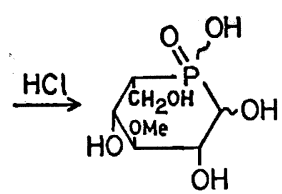

$[16]$

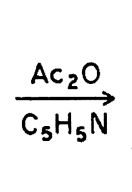

${ }_{5} \mathrm{H}_{5} \mathrm{~N}$

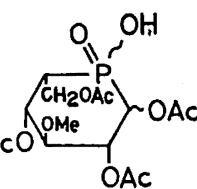

[17]
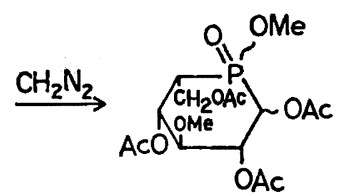

[18]

SDMA : $\left.\mathrm{NaAlH} \mathrm{H}_{2} \mathrm{OCH}_{2} \mathrm{CH}_{2} \mathrm{OMe}\right)_{2}$

よびP 上の立体化学については，今のところ決定できないが，そ れぞれ $\alpha$-抽び $\beta$-アノマー, 㧊よび $(R)$ 一㧊よび $(S)$-体を 含むむのと思われる。

ニトロエノース [5]とホスホン酸ジメチルとの付加物 $[6 \mathrm{~d}]$ のニトロ基をオゾンによる方法を用いて処理し, 対応するアルデ ヒド〔14〕に $68 \%$ の収率で変換した。ジヒドリドビス(2-メトキ シェタノラト)アルミン酸ナトリウム (SDMA) により二つの官 能基を同時に還元し，つついて $0.7 \mathrm{~mol} \cdot \mathrm{dm}^{-3}$ 塩酸で加水分解 し，無水酢酸によるアセチル化およびジアゾメタンによるエステ ル化を行ならと， 1, 2,4,6-テトラーO-アセヂー5-デオキシ-3-Oメチル-1, 5-C-(メトキシホスフィニリデン)-L-イドース [18]が 得られた。ニトロ化合物 $[6 \mathrm{~d}]$ からの収率は $12 \%$ であった。

\section{3 実験}

融点は柳本ミク口融点測定装置により測定した。IR スペクト ルは日本分光 A-3 型赤外分光計により測定した。 ${ }^{1} \mathrm{H}-\mathrm{NMR}$ スペ クトルは日立 R-24 型または R-24 B 型 $(60 \mathrm{MHz})$ により， TMS を内部基準として測定した。質量スペクトルは日立 RMU 7 M GC-MS 質量分析計を用いた。旋光度は日本分光 DIP-4 型 デジタル旋光計により測定した。高速液体クロマトグラフィーは 日本分光 UNIFLOW-211 を用いた。
3.1 (1-メチル-2-ニトロエチル)ジフェニルホスフィンオキシ ト [2 a $]$ 合成

乾燥 THF (15 ml) に溶かした 1-ニトロ-1-プロペン37) 40) $(1.04 \mathrm{~g})$ にジフェニルホスフィンオキシド41) $(2.42 \mathrm{~g})$ の朁燥 $\mathrm{THF}(5 \mathrm{ml})$ 溶夜を $0^{\circ} \mathrm{C}$ で加えたのち, 室温で 2 時間反応を行な った。溶媒を減圧下除去し, 残留物を四塩化炭素から再結晶する

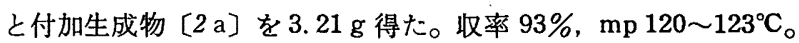
IR $: \nu_{\max }^{\mathrm{KBr}}\left(\mathrm{cm}^{-1}\right): 1550,1440,1370,1180,710$

${ }^{1} \mathrm{H}-\mathrm{NMR} \delta\left(\mathrm{CDCl}_{3}\right): 1.24$ (dd, $\left.3 \mathrm{H}\right), 3.1 \sim 3.7(\mathrm{~m}, 1 \mathrm{H})$, $4.52(\mathrm{dd}, 2 \mathrm{H}), 7.0 \sim 8.1(\mathrm{~m}, 10 \mathrm{H})$ 分析値 C $62.38 \% ， \mathrm{H} 5.58 \% ， \mathrm{~N} 4.89 \%$

37) M. Masui, H. Sayo, J. Pharm. Soc., 4, 332(1956).

38) a) G. D. Buckley, J. L. Charlish, J. Chem. Soc., 1947, 1472.

b) C. E. Redeman, S. W. Chaikin, R. B. Frearing, $J$. Am. Chem. Soc., 70, 2582(1948).

39) a) N. Levy, C. W. Scaife, A. E. W. Smith, J. Chem. Soc., 1948, 52.

b) C. T. Bahner, H. T. Kite, J. Am. Chem. Soc., 71, 3598(1949).

40) D. E. Worrall, Org. Synth. Coll. Vol I, 413(1941).

41) United Kingdom Atomic Energy Authority, Fr 1, 314, 704(1963) ; Chem. Abstr., 59, 2860 b(1963). 


\section{$\mathrm{C}_{15} \mathrm{H}_{18} \mathrm{NO}_{3} \mathrm{P}$ としての}

計算値 C $62.28 \%, \mathrm{H} 5.58 \%, \mathrm{~N} 4.84 \%$

3.2 (1-ホルミルエチル)ジフェニルホスフィンオキシド [3 a] の合成

化合物 [2 a $(1.00 \mathrm{~g})$ の㛺燥メタノール溶液 $(30 \mathrm{ml})$ をナト リウムメトキシド $(0.19 \mathrm{~g})$ と 10 分間処理し, その溶液を $-78^{\circ} \mathrm{C}$ に冷却した。オン゙ンを 30 分間通したのち窒素気流を通してから 硫化ジチル $(5 \mathrm{ml})$ を加えた。反応混合物を徐々に室温とし，16 時間放置した。エバポレーターで低沸点物を除去し, 残留物をク ロロホルムに溶かした。クロロホルム溶夜、水洗し，乾燥してか ら隇圧下で溶媒を留去した。残留物を四塩化炭素から再結晶する

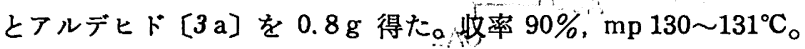
IR $\nu_{\max }^{\mathrm{KBr}}\left(\mathrm{cm}^{-1}\right): 1720,1650$

${ }^{1} \mathrm{H}-\mathrm{NMR} \delta\left(\mathrm{CDCl}_{3}\right): 1.34(\mathrm{dd}, 3 \mathrm{H}), 3.3 \sim 3.8(\mathrm{~m}, 1 \mathrm{H})$, $7.2 \sim 8.0(\mathrm{~m}, 10 \mathrm{H}), 9.84(\mathrm{~d}, 1 \mathrm{H})$

分析値 C $69.79 \%$, H $5.85 \%$

$\mathrm{C}_{15} \mathrm{H}_{15} \mathrm{O}_{2} \mathrm{P}$ としての

計算值 C $69.97 \% ，$ H $5.86 \%$

化合物 [2 a $](1.00 \mathrm{~g})$, ローズベンガル $(0.004 \mathrm{~g})$ ，ナトリウ ムメトキシド $(0.37 \mathrm{~g})$ の乾燥メタノール $(30 \mathrm{ml})$ 溶液を酸素気 流下 $-78^{\circ} \mathrm{C}$ でタングステンランプ ( $\left.300 \mathrm{~W} \times 2\right)$ で光照射しオン゙ ンと同様の後処理をするとアルデヒド〔3a]を収率 $90 \%$ で得 た。

3.3 (2-ヒドロキシ-1-メチルエチル)ジフェニルホスフィンオ キシド $[\mathbf{a}$ a $]$ の合成

化合物 [3 a $](0.415 \mathrm{~g})$ の㲦燥メタノール溶液 $(25 \mathrm{ml})$ に水素 化ホウ素ナトリウム $(0.612 \mathrm{~g})$ を加え 16 時間加熱還流したのち 少量の水を加えさらに 30 分間還流した。反応混合物を酢酸で中 和ののち，溶媒を除去した。残留物をクロロホルムに溶かし，ク 口ロホルム溶液を水洗し乾燥ののち溶媒を除去した。ク口品ホル ムーシクローキサンから再結晶し华合物 [4a]を収率 $82 \%$ ，で得 た。 $\mathrm{mp} 141 \sim 142^{\circ} \mathrm{C}_{\text {。 }}$

IR $\nu_{\max }^{\mathrm{KBr}}\left(\mathrm{cm}^{-1}\right): 3200,1440,1160,720$.

${ }^{1} \mathrm{H}-\mathrm{NMR} \delta\left(\mathrm{CDCl}_{3}\right): 1.22(\mathrm{dd}, 3 \mathrm{H}), 2.4 \sim 3.0(\mathrm{~m}, 1 \mathrm{H})$, $3.83(\mathrm{dd}, 2 \mathrm{H}), 4.46(\mathrm{~s}, 1 \mathrm{H}), 7.3 \sim 8.0(\mathrm{~m}, 10 \mathrm{H})$

MS $m / z: 260\left(\mathrm{M}^{+}\right)$

分析值 260.0970

$\mathrm{C}_{15} \mathrm{H}_{17} \mathrm{O}_{2} \mathrm{P}$ としての

部算値 260.0966

元素分析 :

分析値，C $68.96 \% ， \mathrm{H} 6.34 \%$

$\mathrm{C}_{15} \mathrm{H}_{17} \mathrm{O}_{2} \mathrm{P}$ としての

計算値 C $69.22 \% ， \mathrm{H} 6.58 \%$

$3.45,6$-ジデオキシ-5-C-(ジフェニルホスフィニル)-1, 2-0イソプロビリテン-3-O-メチル-6-C-ニトロ- $\beta-\mathrm{L}-$ イトフフラー ス $[6 \mathrm{a}$, ido $]$ の合成

エノース $[5]^{42)}(2.00 \mathrm{~g})$ とジフニルホスフィンオキシドを 窒素雾囲気下乾燥 THF $(25 \mathrm{ml})$ 中で室温で 1 日反応させた。溶

42) a) J. M. Großheintz, H. O. L. Fischer, J. Am. Chem. Soc., 70, 1476(1948),

b) R. L. Whistler, R. E. Pyler, Carbohydr. Res., 12, 201(1970).
媒を減圧下に除去し, 残留物をシリカゲルカラムクロマトグラフ ィーで分離し,さらにクロロホルムーシクロヘキサンから再絬晶 して [6 a ido]を収率 $40 \%$ で得た。 $\mathrm{mp} 149 \sim 150^{\circ} \mathrm{C}$ 。 $[\alpha]_{\mathrm{D}}^{26}-49.8^{\circ}(c 1.02, \mathrm{MeOH})$ 。

IR $\nu_{\max }^{\mathrm{KBr}}\left(\mathrm{cm}^{-1}\right): 1555,1440,1375,1190,720$

${ }^{1} \mathrm{H}-\mathrm{NMR} \delta\left(\mathrm{CDCl}_{3}\right): 1.20(\mathrm{~s}, 6 \mathrm{H}), 3.38(\mathrm{~s}, 3 \mathrm{H}), 3.7 \sim$ $5.1(\mathrm{~m}, 6 \mathrm{H}), 5.75(\mathrm{~d}, 1 \mathrm{H}), 7.2 \sim 8.2(\mathrm{~m}, 10 \mathrm{H})$

MS $m / z: 447\left(\mathrm{M}^{+}\right)$

分析値 C $58.92 \% ， \mathrm{H} 5.82 \% ， \mathrm{~N} 3.03 \%$ $\mathrm{C}_{22} \mathrm{H}_{26} \mathrm{NO}_{7} \mathrm{P}$ としての

計算值 C $59.06 \% ， \mathrm{H} 5.86 \%$ Ｎ $3.13 \%$

3.5 6-オキソ-5-デオキシ-5-C-(ジフェニルホスフィニル)-

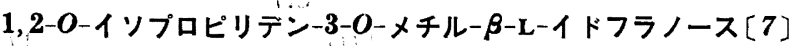
の合成

化合物 $[6 \mathrm{a}, i d o](1.00 \mathrm{~g})$ ，とナトリウムメトキシド $(0.12 \mathrm{~g})$ の渂燥メタゔ-ル溶液を用いて 3.2 と同様な方法でニトロ基の 変換を行ないD-gluco-誘導体とともに生成物〔7〕を $92 \%$ の収 率で得た。

IR $\nu_{\max }^{\text {neat }}\left(\mathrm{cm}^{-1}\right): 1770,1440,1190,720$

${ }^{1} \mathrm{H}-\mathrm{NMR} \delta\left(\mathrm{CDCl}_{8}\right): 1.34,1.48(2 \mathrm{~s}, 6 \mathrm{H}), 3.40(\mathrm{~s}, 3 \mathrm{H})$, $3.7 \sim 4.8(\mathrm{~m}, 4 \mathrm{H}), 6.04(\mathrm{~d}, 1 \mathrm{H}), 7.0 \sim 8.2(\mathrm{~m}, 10 \mathrm{H})$, $9.90(\mathrm{~d}, 1 \mathrm{H})$

3.6 5-デオキシ-5-C-(ジフェニルホスフィニル)-1, 2-O-1 ソプロピリデン-3-O-メチル- $\boldsymbol{\beta}-\mathbf{L}-$ イドフラノース [8]の合成

化合物 [7] $(0.90 \mathrm{~g})$ の乾燥丈夕ノール $(30 \mathrm{ml})$ 溶液に水素化 ホウ装ナトリウム $(0.82 \mathrm{~g})$ を加えて 16 時間加熱還流した。反応 混合物を 3.3 と同様にして後処理したのち, シリカゲルカラムク ロマトグラフィーにて分離し，クロロホルムーシクロヘキサンか ら再結晶すると生成物〔8〕が $34 \%$ の収率で得られた, mp 175 $\sim 176^{\circ} \mathrm{C}_{\text {。 }}$

$[\alpha]_{\mathrm{D}}^{26}-17.7^{\circ}(c 1.01, \mathrm{MeOH})$ 。

IR $\nu_{\max }^{\mathrm{KBr}}\left(\mathrm{cm}^{-1}\right): 3250,1440,1170,720$

${ }^{1} \mathrm{H}-\mathrm{NMR} \delta\left(\mathrm{CDCl}_{3}\right): 1.15,1.20(2 \mathrm{~s}, 6 \mathrm{H}), 3.40(\mathrm{~s}, 3 \mathrm{H})$, $3.7 \sim 4.6(\mathrm{~m}, 7 \mathrm{H}), 5.70(\mathrm{~d}, 1 \mathrm{H}), 7.2 \sim 8.1(\mathrm{~m}, 10 \mathrm{H})$ MS $m / z: 418\left(\mathrm{M}^{+}\right)$ 分析値 418.1551

$\mathrm{C}_{22} \mathrm{H}_{27} \mathrm{O}_{6} \mathrm{P}$ としての

元素分析：計算值 418.1545

分析值 C $62.90 \%, \mathrm{H} 6.20 \%$

$\mathrm{C}_{22} \mathrm{H}_{27} \mathrm{O}_{6} \mathrm{P}$ としての

計算值 C $63.15 \%, \mathrm{H} 6.50 \%$

3.7 6-O-アセチル-5-デオキシ-5-C-(ジフェニルホスフィニ

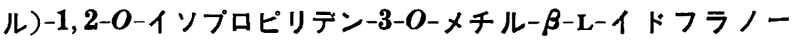
ス [9]の合成

化合物 [8] $(0.230 \mathrm{~g})$ をピリジン $(5 \mathrm{ml})$ に溶かし, 無水酢酸 $(3 \mathrm{ml})$ を加克, 室温で 24 時間反応させた。通常の後処理ののち, シリカゲルの TLC にて分儶し，化合物〔9]を $10 \%$ の収率で 得た, $[\alpha]_{\mathrm{D}}^{27}-22.3^{\circ}\left(c 0.51, \mathrm{CHCl}_{3}\right)$ 。

IR $\nu_{\max }^{\text {neat }}\left(\mathrm{cm}^{-1}\right): 1740,1440,1190,720$

${ }^{1} \mathrm{H}-\mathrm{NMR} \delta\left(\mathrm{CDCl}_{3}\right): 1.19(\mathrm{~s}, 6 \mathrm{H}), 1.68(\mathrm{~s}, 3 \mathrm{H}), \quad 3.35$ $(\mathrm{s}, 3 \mathrm{H}), 3.4 \sim 4.7(\mathrm{~m}, 6 \mathrm{H}), 5.64(\mathrm{~d}, 1 \mathrm{H}), 7.2 \sim 8.0(\mathrm{~m}$, $10 \mathrm{H}$ ) 


$$
\begin{aligned}
& \text { MS } m / z: 460\left(\mathrm{M}^{+}\right) \\
& \text {分析值 } 460.1703 \\
& \mathrm{C}_{24} \mathrm{H}_{29} \mathrm{O}_{7} \mathrm{P} \text { としての } \\
& \text { 計算值 } 460.1652
\end{aligned}
$$

$3.81,2,4,6$-テトラ-O-アセチル-5-デオキシ-3-O-メチル-1, 5-C-(フェニルホスフィニリテン)-L-イドース[13]の合成

付加物 $[6 \mathrm{~b}, i d o](1.40 \mathrm{~g})$ の THF $(10 \mathrm{ml})$ 溶液に $0.7 \mathrm{~mol}$. $\mathrm{dm}^{-3}$ 塩酸 $(50 \mathrm{ml})$ を加之，窒素票囲気下で 3 時間加爇還流のの ち，減圧下で水を留去した。残留物を $50 \mathrm{ml}$ の水に溶かしイオン 交換樹脂アンバーライト IRA-410 で処理した。ふたたび減圧下 で水を除去して化合物 [10]を $82 \%$ の収率で得た。化合物 [10] $(0.82 \mathrm{~g})$ とナトリウムメトキシド $(0.14 \mathrm{~g})$ を乾燥入夕ノール $(30 \mathrm{ml})$ に溶かし 3.2 の方法と同様にしてアルデヒド〔11]を定 量的に得た。 $[11](0.78 \mathrm{~g})$ の乾燥メタノール $(25 \mathrm{ml})$ 溶液に水 素化ホウ素ナトリウム $(0.99 \mathrm{~g})$ を加え 3.3 の方法と同様にして アルコール [12]を得, つづいてピリジン $(10 \mathrm{ml})$ と無水酢酸 $(6$ $\mathrm{ml}$ ) を用い室温で 3 日間反応させ 3.7 の方法と同様の方法によ り処理をしたのち，シリカゲルカラムクロマトグラフィーにより 分離して [13] を全収率 $3.2 \%$.で得た， $[\alpha]_{\mathrm{D}}^{17}+1.05^{\circ}$ (c0.86, $\mathrm{CHCl}_{3}$ )。

IR $\nu_{\max }^{\text {neat }}\left(\mathrm{cm}^{-1}\right): 1750,1440,1180,720$

${ }^{1} \mathrm{H}-\mathrm{NMR} \delta\left(\mathrm{CDCl}_{3}\right): 2.08,2.18(2 \mathrm{~s}, 12 \mathrm{H}), 3.64,3.83(2$ $\mathrm{s}, 3 \mathrm{H}), 3.9 \sim 4.5(\mathrm{~m}, 3 \mathrm{H}), 4.9 \sim 5.3(\mathrm{~m}, 2 \mathrm{H}), 5.48,6.13$ $(2 \mathrm{~d}, 1 \mathrm{H}), 5.95,6.00(2 \mathrm{~d}, 1 \mathrm{H}), 7.1 \sim 8.9(\mathrm{~m}, 5 \mathrm{H})$ MS $m / z: 470\left(\mathrm{M}^{+}\right)$

$3.91,2,4,6$-テトラーO-アセチル-5-デオキシ-3-O-メチル-1, 5-C-(メトキシホスフィニリデン)-L-イドース [18]の合成 化合物 $[6 \mathrm{~d}](1.20 \mathrm{~g})$ をメタノール $(25 \mathrm{ml})$ に溶かし, ナト リウムメトキシド $(0.275 \mathrm{~g})$ を加え 3.2 と同様の方法によりフ ルデヒド〔14〕を $68 \%$ の収率で得た。アルデヒド〔14](0.70g) の $\mathrm{THF}(50 \mathrm{ml})$ 溶液に SDMA $(2.7 \mathrm{~g})$ を加え $0^{\circ} \mathrm{C}$ で 2 時間反 応させたのち，希塩酸により弱酸性にして 24 時間加熱還流した。 反応後溶媒を除去し, 残留物にピリシン $(50 \mathrm{ml})$ と無水酢酸 (30 $\mathrm{ml}$ ) を加兄室温で7日間かきまぜた。反応混合物にクロロホルム を加光，不溶解物を汇別し，減圧下で低沸点物を除去した。残留 物をシリカゲルカラムクロマトクラフィーにより分離し，ジアデ メタンで処理すると化合物〔18〕が全収率 12\% で得られた。

IR $\nu_{\max }^{\text {neat }}\left(\mathrm{cm}^{-1}\right): 1740,1260,1180,1040,720$

${ }^{1} \mathrm{H}-\mathrm{NMR} \delta\left(\mathrm{CDCl}_{3}\right): 1.90(\mathrm{~s}, 12 \mathrm{H}), 3.1 \sim 3.4(\mathrm{~m}, 1 \mathrm{H})$, $3.12,3.20(2 \mathrm{~s}, 3 \mathrm{H}), 3.38(\mathrm{~d}, 3 \mathrm{H}), 3.7 \sim 4.0(\mathrm{~m}, 3 \mathrm{H})$, $4.0 \sim 4.2(\mathrm{~m}, 1 \mathrm{H}), 4.6 \sim 5.1(\mathrm{~m}, 1 \mathrm{H}), 5.4 \sim 5.8(\mathrm{~m}, 1 \mathrm{H})$ MS $m / z: 424\left(\mathrm{M}^{+}\right)$

元素分析に御協力頂きました三共株式会社の木所正夫, 佐伯博 道両氏に謝意を表します。

\title{
Special Articles on Organic Chemistry of Heteroatoms
}

\section{Functional Group Interconversion of a $\boldsymbol{\beta}$-Nitro Group of Phosphorus Compounds and Synthesis of Some Phosphino Sugars}

\author{
Mitsuji Yamashita*, Manabu Yamada, Motoyuki Sugiura, \\ Hiroyuki Nomoto and Tatsuo Oshikawa \\ Department of Applied Chemistry, Faculty of Engineering, \\ Shizuoka University; Hamamatsu-shi 432 Japan
}

\begin{abstract}
Addition reactions of phosphorus compounds having a $\mathrm{H}-\mathrm{P}$ bond with nitroalkenes gave $\mathrm{C}-\mathrm{P}$ compounds. The functional group interconversions of the nitro group by the Nef and some other related reactions were unsuccessful. Reaction of ozone or singlet oxygen with the nitro group provided the corresponding aldehyde, which was further converted into the corresponding alcohol by reduction with sodium borohydride or sodium cyanotrihydroborate. The present method thus provides a new synthetic route for the preparation of $\beta$-hydroxy phosphorus compounds. Some phosphino sugar derivatives, i. e.,6-O-acetyl-5-deoxy-5-C(diphenylphosphinyl)-1, 2- $O$-isopropylidene-3- $O$-methyl- $\beta$-L-idofuranose, , , 1, 2, 4, 6-tetra- $O$ acetyl-5-deoxy-3-O-methyl-1, 5-C-(phenylphosphinylidene)-L-idose, and 1, 2, 4, 6-tetra-O-acetyl -5-deoxy-3-O-methyl-1, 5-C-(methoxyphosphinylidene)-L-idose, were synthesized from adducts of phosphorus compounds and the nitroenose derivatives. The latter two compounds have the phosphorus atom in their hemiacetal rings.
\end{abstract}

